\title{
Nanostructured coated powders for structural net shape components
}

\author{
J.M. Castanho*, M.T. Vieira, M. Matos, B. Trindade \\ ICEMS-Materials and Surface Engineering Group, Mechanical Engineering Department, Polo II, University of Coimbra, Coimbra, Portugal
}

Available online 6 October 2006

\begin{abstract}
The specific goal of the present study is to evaluate the surface performance of thin films based on sputtered stainless steel (304 AISI) deposited on dissimilar $(\mathrm{Cu})$ and similar powder materials (316 AISI) with different size distributions and shapes. The covering efficiency, the surface morphology and the grain size, and their impact on the flowability of powders, are studied. The most important role of powder surface treatments is attained when spherical powders of copper were coated with a nanocrystalline thin film of stainless steel, the flowability increases by $80 \%$. However, in the stainless steel powders the presence of a similar coating has relevance only for irregular particles, where a $25 \%$ flowability improvement is measured.
\end{abstract}

(C) 2006 Elsevier B.V. All rights reserved.

Keywords: Thin films; Surfaces and interfaces; Powder metallurgy; Metals and alloys

\section{Introduction}

New powder technologies are emerging, such as net shape fabrication where a component could be obtained if powders - without any constriction resulting from shape forming are consolidated subsequently. Economical exigency obliges to optimize the powder characteristics in order to attain the minimum distance between particulate powders. It is not enough to select the best powder size distribution and particle shapes, the surface morphology and the crystallite size could also have a main role in the consolidation of powders by different technologies of net shaping, contributing to the improvement of the final density without requiring other expensive treatments.

The net shape requirements in metal structural parts compel to $\mathrm{P} / \mathrm{M}$ processing route depending on the resolution of three main interdependent problems: flowability, full density and shrinkage control. Flowability depends essentially on particles' size and inter-particle friction and attractive forces; full density and shrinkage depend mainly on the inter-particle distances and diffusion mechanisms. All the surface powder modification processes that induce suitable surface changing in order to obtain a sound component are welcome. Among the processes of powder surface modification [1,2], sputtering deposition is one of the

\footnotetext{
* Corresponding author.

E-mail addresses: jose.castanho@dem.uc.pt (J.M. Castanho), teresa.vieira@dem.uc.pt (M.T. Vieira), bruno.trindade@dem.uc.pt (B. Trindade).
}

most promising [3], because it may associate high efficiency of coating powders, maintaining or not their chemical composition, with high surface characteristics due to a significant decrease of the crystallite size, which is suitable to decrease the friction coefficient and improve the diffusion rate.

\section{Experimental details}

Gas and water atomised copper and stainless steel (316 AISI) powders were coated with sputtered stainless steel (304 AISI) target, by a home-manufactured dc magnetron sputtering equipment with a deposition chamber modified in order to promote the an efficient coating of all surface powders. The main sputtering conditions selected were as follows: substrate weight, $50 \mathrm{~g}$; target-to-substrate distance, $150 \mathrm{~mm}$; deposition pressure, $0.5 \mathrm{~Pa}$; deposition power density, $16.7 \mathrm{~kW} / \mathrm{m}^{2}$.

In order to determine the morphology of the coatings glass substrates were used and the coating was removed for scanning electron microscopy (SEM) visualization. The coated powder density and the particle size distribution were evaluated by using helium pycnometry Accupic 1330 and by Laser diffraction Coulter LS 130, respectively. The chemical composition of the powders was evaluated by electron probe microanalysis (EPMA) Cameca SX50 and by EDXS. Finally, the flowability of the powders was determined by using a Flodex apparatus [4].

\section{Results and discussion}

The stainless steel (SS) coatings were previously sputtered on flat bulk substrates to evaluate their chemical composition and morphology. The EPMA analysis revealed the replication of the chemical composition of the targets in the coatings, which confirms the magnetron sputtering as a powerful deposition 
(a)

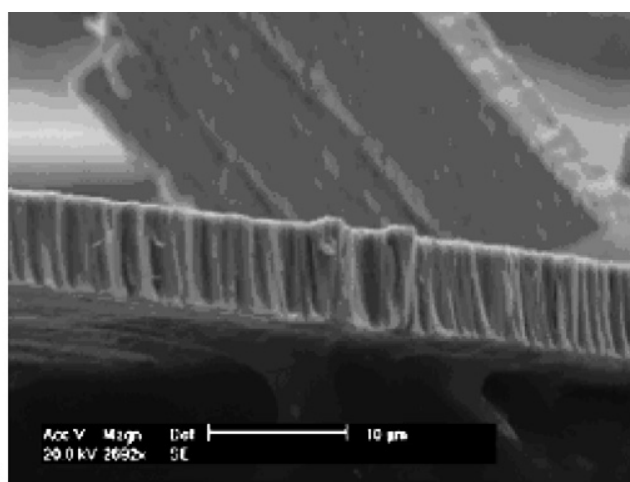

(b)

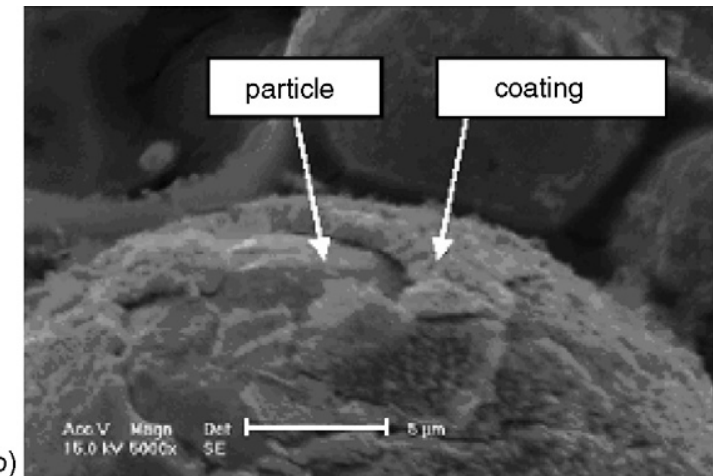

Fig. 1. Morphology of stainless steel coating deposited: (a) on glass substrates and (b) in a particle powder. technique to transfer the multi-element composition of the targets to the coating without significant loss of stoichiometry. The chemical composition of the coatings for different powders is similar to the stainless steel target.

The visualization of the coatings deposited on flat bulk substrates by SEM showed columnar morphology (Fig. 1), with a

(a)

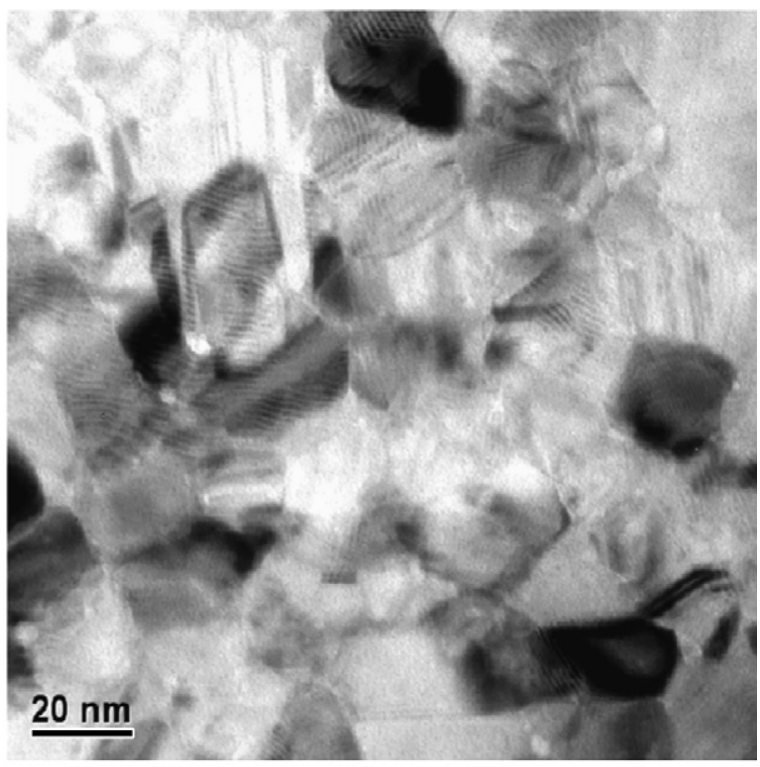

(b)

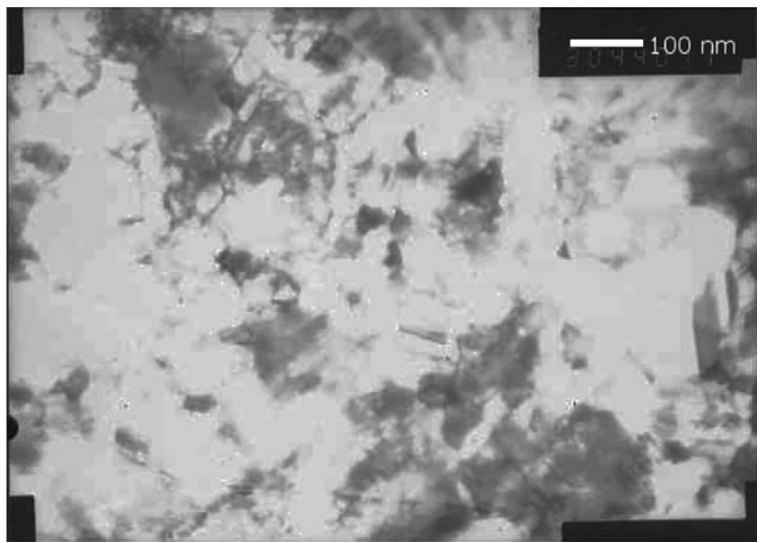

Fig. 2. (a) Crystallite size of metal coatings deposited on thermal conductive substrate (copper) and (b) crystallite size metal coatings deposited on non-thermal conductive substrate (glass). high density of inter-columnar voids. This type of morphology is due to the low substrate temperature, the high deposition pressures and unbiased substrate. The density of the stainless steel (304L AISI) coating deposited on glass substrate is $6690 \mathrm{~kg} / \mathrm{m}^{3}$, which is approximately $84 \%$ of the theoretical stainless steel density $\left(7960 \mathrm{~kg} / \mathrm{m}^{3}\right)$. This difference in the density values can be attributed to the nanoporosity of the coatings (16\%), which agrees with their dense columnar morphology. For the same deposition conditions the crystallite size of the stainless steel coatings is strongly dependent on the thermal characteristics of the substrates. In fact, coatings deposited on high thermal conductivity materials such as copper and on materials with low thermal conductivity like glass present different grain sizes. This was taken into account when comparing the behaviour of coated copper and stainless steel powders. However, the thermal conductivity difference between copper and stainless steel had not a relevant role in the grain size. In both cases the crystallite sizes are nanometric with approximately $20 \mathrm{~nm}$ (Fig. 2a); only for the low thermal conductivity substrates (glass) there is an increase of the crystallite size to values around $100 \mathrm{~nm}$ (Fig. 2b).

The surface analysis of copper and stainless steel powders shows a good surface coating, particularly in copper powders, in stainless steel is difficult to make it out, due to the similar optical characteristics between the coating and the substrate. In coated copper it is highlighted that the spherical or irregular shaped copper powders show a uniform coated surface (Fig. 3).

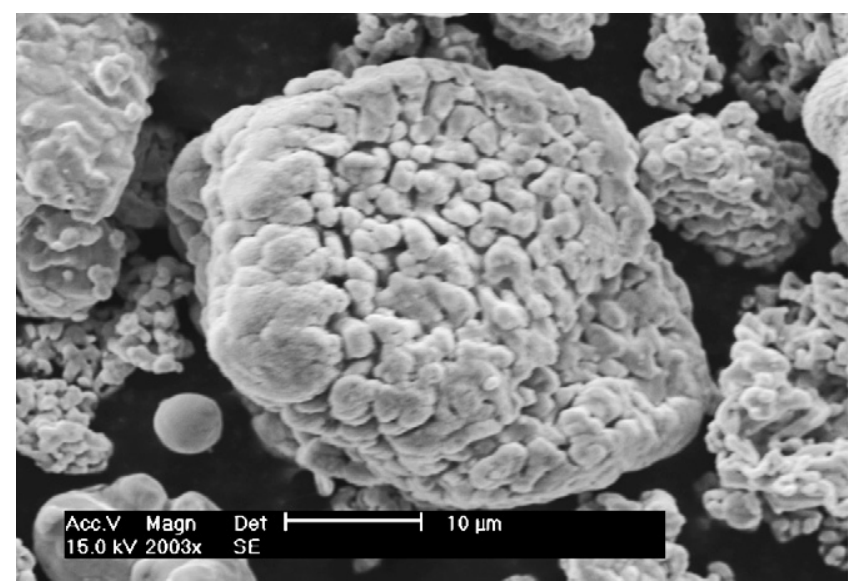

Fig. 3. Morphology of stainless steel coating deposited on copper powders. 
Table 1

Physical characteristics of coated and uncoated powders

\begin{tabular}{|c|c|c|c|c|c|}
\hline Substrate & Coating & $D_{50}(\mu \mathrm{m})$ & $d\left(\mathrm{~kg} / \mathrm{m}^{3}\right) \times 10^{-3}$ & $d_{\text {pour }}\left(\mathrm{kg} / \mathrm{m}^{3}\right) \times 10^{-3}$ & Flowability $^{\mathrm{a}}(\mathrm{Pa})$ \\
\hline Copper (irregular) & Uncoated & $19 \pm 1$ & $8.56 \pm 0.01$ & $2.56 \pm 0.05$ & $50.0 \pm 1.0$ \\
\hline Copper (irregular) & SS (304 AISI) & $20 \pm 2$ & $8.21 \pm 0.03$ & $2.56 \pm 0.07$ & $50.0 \pm 1.5$ \\
\hline Copper (spherical) & Uncoated & $28 \pm 2$ & $8.67 \pm 0.03$ & $4.80 \pm 0.10$ & $190.0 \pm 5.8$ \\
\hline Copper (spherical) & SS (304 AISI) & $31 \pm 2$ & $8.35 \pm 0.04$ & $4.80 \pm 0.10$ & $35.6 \pm 0.8$ \\
\hline SS (316 AISI) (irregular) & Uncoated & $60 \pm 4$ & $7.80 \pm 0.01$ & $2.72 \pm 0.06$ & $26.6 \pm 0.6$ \\
\hline SS (316 AISI) ((irregular) & SS & $61 \pm 4$ & $7.78 \pm 0.01$ & $2.74 \pm 0.03$ & $20.2 \pm 0.2$ \\
\hline SS (316 AISI) (spherical) & Uncoated & $7 \pm 0.5$ & $7.87 \pm 0.01$ & $3.33 \pm 0.04$ & $196.0 \pm 2.6$ \\
\hline SS (316 AISI) (spherical) & SS & $8 \pm 0.6$ & $7.81 \pm 0.01$ & $3.09 \pm 0.01$ & $151.3 \pm 0.1$ \\
\hline
\end{tabular}

${ }^{\text {a }}$ Flowability $=($ poured density $\times$ radius of hole $\times$ gravity acceleration $) / 2$ [4].

The real density $(d)$, the median particle diameter $\left(D_{50}\right)$ and the poured density $\left(d_{\text {pour }}\right)$ of the coated and uncoated powders of copper and stainless steel are summarized in Table 1. In this table are also summarized the densities of uncoated and coated copper and SS powders. The densities of the uncoated powders are closer to the theoretical value, while the density of the coated powders is reduced by the presence of a SS coating, particularly in the copper powders due to the higher difference of densities between coating and powder.

For the same deposition parameters the mobility of sputtered adatoms on copper or on stainless steel is similar, hence it is not expectable that the coating morphology will be different, thus it was chosen the coated copper to evaluate the weight content of SS deposited coating. Therefore, a classical law of mixtures was applied to coated copper powders: $x=\left(\left(d_{\mathrm{cu}}-d_{\text {coat }}\right) /\left(d_{\mathrm{cu}}+d_{\text {coat }}\right)\right) \times(100-p)$; where $x=\%$ of coating; $p=\%$ porosity; $d_{\mathrm{Cu}}=$ density of copper powder; $d_{\text {coat }}=$ density of coated powder. The weight percentage of the coated powders slightly depends on the shape. The weight contents of spherical and irregular shaped copper powders are approximately 13 and $15 \%$, respectively. The deposition conditions, i.e., the presence of an electric field favours the aggregation of the particles, decreasing the broadening of the particle size distribution curves and reducing the possibility of efficiently coating the powder surface. Although the poured densities of the powders are affected by their shape, the existence of a coating on the surface of the powders has no outcoming in copper. In SS powders the coating of spherical ones contributes to a decrease of poured density, approaching them to the values of the irregular forms.
In what concerns the flowability, measured by the equation as follows: $\left(d_{\text {pour }} \times r \times g\right) / 2$ [4], where $d_{\text {pour }}=$ poured density; $r=$ radius of hole; $g=$ gravity acceleration; an excellent improvement of spherical powders of copper coated with a nanocrystalline thin film of stainless steel is attained (80\%). However, in the stainless steel powders the presence of a similar coating has relevance only for irregular particles, where a $25 \%$ flowability increase is measured.

\section{Conclusions}

The sputtering technique is a suitable process for coating metallic powders, maintaining or not their chemical composition, promoting a significant decrease of the surface grain size, which becomes nanometric. The new grain sizes associated to a new surface morphology contribute to an important change of the powders' surface properties. It is demonstrated that the flowability of the powders can be strongly improved by the presence of a thin film of a dissimilar material in spherical copper particles. The same coatings deposited in similar materials increase the flowability, mainly in irregular shapes, but not so significantly than the evaluated in copper powders.

\section{References}

[1] O.A. Harizanov, P.L. Stefchev, A. Iossifova, Mater. Lett. 33 (1998) 297-299.

[2] T. Abe, S. Akamaru, K. Watanabe, J. Alloys Compd. 377 (2004) 194-201.

[3] C.M. Fernandes, V.M. Ferreira, A.M.R. Senos, M.T. Vieira, Surf. Coat. Technol. 176 (2003) 103-108.

[4] A. Gioia, Flodex Technical Bulletin, Hanson Research Corporation, February $1980,1-4$. 